\title{
An Opinion 11,000km in the Making
}

\author{
Michael Tyler Pratte
}

Faculty of Medicine, University of Ottawa, Ottawa, Ontario, Canada

ABSTRACT

How is medicine practiced on the other side of the world? As medical students in Canada, we learn much about disease pathophysiology and the North American healthcare system. Yet important observations made about how other cultures deliver care can be used to help us address our own shortcomings. In this opinion piece, I use my experience studying cardiac surgery in Shanghai, China to explore how both China and Canada confront a common problem: access to care in rural communities. Despite their differences, each country arrive at creative solutions, reflecting the incredible diversity of their patients.

RÉSUMÉ

Comment la médecine est-elle pratiquée à l'autre bout du monde? En tant qu'étudiants en médecine au Canada, nous apprenons beaucoup sur la physiopathologie des maladies et sur le système de santé nord-américain. Cependant, des observations importantes sur la manière dont les autres cultures fournissent des soins de santé peuvent être utiles afin de nous aider à remédier à nos propres faiblesses. Dans cet article d'opinion, j'utilise mon expérience lors de mes études en chirurgie cardiaque à Shanghai, en Chine, afin d'explorer comment le Canada et la Chine font face à un problème commun: I'accès aux soins de santé dans les communautés rurales. Malgré leurs différences, chaque pays parvient à des solutions créatives, reflétant l'incroyable diversité de ses patients.

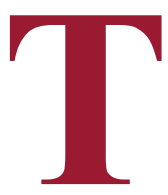

he patients stood lined up one after another in front my preceptor's desk. Outside the room, mayhem reigned, with many similar lines spilling into the hallway and confusing the hot, exhausted people waiting to be seen. "You see, we do things a little different here," said my preceptor, a cardiac surgeon, as he finished with one patient at the desk who was immediately replaced by another. It was a busy day in the cardiac surgery clinic of Renji Hospital, Shanghai, with over thirty patients to be seen in hardly an hour, and a dozen angiograms booked for later that afternoon; however, not any busier than most other days, my preceptor assured me. But still, I couldn't help but feel a little culture-shocked. Pushed by massive queues that extended into the hospital lobby, many patients crowded into the same room we were seeing our current patients in. What about confidentiality, I wondered, with some uneasiness. More than that, what about their care? My preceptor seemed to have a superhuman ability to greet patients, understand their concerns, address them - all within minutes. Even more baffling, he somehow managed to find the time to catch up with old friends and teach me as well (in a different language, no less)! Whatever he was doing, it was working. By the end of the clinic, the examination bed was piled high with gifts of teas and fruits from grateful patients. He collapsed in his chair, rubbed his face with his hands, then suddenly got up and clapped his hands. "Alright," he said cheerfully, "It's time for a smoke!" A little different here, indeed.
This July, I had the fantastic opportunity to do a placement at Jiao Tong University in Shanghai, China as part of University of Ottawa's Global Health program. It was an exciting prospect; having been accepted into both this and our school's Medicine and Humanities' International Summer School, also in Shanghai, I would be spending over a month in the city to learn about the practice of "Western Medicine" and Traditional Chinese Medicine (TCM). Despite my excitement, I was also intimidated. I had never been to Asia, did not speak Mandarin, knew close to nothing about Chinese Medicine, and only slightly more about Western Medicine, for that matter! It felt like no time at all until I was packing and on my way to what would become the best trip I have ever had. My placements were scheduled so that I would begin with two weeks studying the humanities, the arts, TCM, and how these all intersected with the practice of medicine in North America. The second part, at Renji Hospital, was meant to be more along the lines of our placements in Ottawa - but even that, I was soon to learn, was not quite what I had anticipated.

I must admit - despite our interest in the humanities, most of us in the summer school, myself included, soon found ourselves struggling to understand what things like Chinese opera and poetry had to do with medicine. We all loved the humanities, but how would Madame Butterfly help us care for patients? As I discussed these questions with my preceptor later on, the answer began to form; over $43 \%$ of China's massive population

Keywords: China, Canada, Global Health, Access, Alternative Medicine 
of 1.4 billion live in rural areas (1). Many face poverty and seek better opportunities, including more advanced medical care, in larger cities such as Shanghai. The result is a noticeable dichotomy between rural and urban medicine. With more than 1600 admissions per day, most Chinese metropolitan hospitals face incredible patient loads (2). The reason for this is simple; despite China's large population, only a handful of hospitals in the country offer services for complicated conditions this was particularly true at Renji Hospital. Furthermore, due to poverty and the large distance from medical care, many patients neglect their symptoms and only present to hospitals at a critical stage. For example, a patient with an abdominal aortic aneurysm may only present to the hospital when the aneurysm has ruptured. The result was striking. I regularly saw more aortic dissections, a condition with a very low incidence, in half a day than I could count on both hands. This should sound familiar to healthcare professionals practicing in North America. Canada faces many of the same issues in providing medical care to rural areas. In particular, our northern regions often struggle with access to care (3). In fact, despite our belief that infectious diseases are well-managed in Canada, some infamous and deadly diseases, such as tuberculosis, heave reached epidemic levels in Northern Canada in recent years (4).

Well, how do our eastern counterparts respond to barriers in accessing care? Due to the difficulties of getting to hospital and being seen, the Chinese people have sought out other methods to treat their woes, many of which involve the use of alternative medicine. In addition to legendary art and folklore, Chinese culture has some of the most diverse and longstanding techniques of traditional medicine, some of them so popular that they have secured a place amongst Western social mores. Acupuncture, tai chi, and herbal products, to name a few, make up common remedies the population uses on a frequent basis to supplement - and sometimes replace - our Western treatments. The allure is obvious; simple, longstanding remedies that not only calm the body, but also calm the soul. Acupuncture, for example, can be found all across China, and in most major cities around the world. Alternative medicine practices are also usually more affordable for patients, especially those that lack publicly-funded health care, and fulfill a desperate need for spirituality and hope that Western Medicine sometimes loses in its long lines of patients. Yet there is still the million-dollar question; does it work? The truth of the matter is that TCM has been tested vigorously by Western scientists and the results are mixed. The debate is ongoing, and whether there is a physiological basis to these treatments is beyond the scope of this article. What we do know is this: traditional medicine is here to stay, and arguing against it will not make it go away.

In the face of the ongoing popularity of TCM, the Chinese healthcare system has evolved in interesting ways. Rather than looking down upon alternative medicines, which can frequently be seen in places like North America, the Chinese have taken steps to embrace TCM. Many hospitals in China, for example, have begun to create hybridized centers offering both Western and Traditional Chinese Medicine. In fact, TCM herbs were requested in as many as $70 \%$ of outpatients in these combined hospitals, a testament to their ongoing popularity (5). Some Chinese universities even offer degrees in TCM, much like the path to an M.D. Moreover, significant scientific research is being conducted in an attempt to isolate and amplify the active ingredients in herbal remedies.

In contrast, Canada has tackled rural medicine differently. This year, the Canadian Medical Association (CMA) has launched a task force to explore ways to develop telemedicine, the delivery of medicine remotely through audiovisual technologies (6). Despite being a potentially strong solution to the issue of access to care, some have criticized Canada's use of telemedicine as poor (7). With Canada's size and brutal winters, forcing the ill and the frail to trek to clinics for check-ups is fraught with dangers. In Northern Canada, where patients face even harsher weather and greater travel distances, it is easy to see why health expectancy, an indicator often used as a proxy for quality of life, is lower for those patients than their southern counterparts (3). Telemedicine is by no means a universal solution, but it is a step in the right direction. Perhaps Canada should also look eastward for some advice on how to deal with our ongoing issues in access to care by providing physicians more education on alternative medicines. Experience with and integration of alternative medicine could not only avoid the antagonism and unease many physicians feel when they are brought up, but also, in the case of acupuncture for example, help certain populations of patients such as those suffering from chronic pain (8). Repeating doctor visits for untreatable pain can be frustrating to patients, who may feel like they have tried everything already, and add more visits to an already backlogged physician schedule. In contrast, some alternative medicines have been shown to decrease the need for health care visits (9). Furthermore, education on alternative 
medicines will serve to increase physician cultural awareness and spirituality. This would make physicians more comfortable helping different peoples from around the world, something especially important in Canada's diverse population.

Ultimately, while medicine may be done quite differently in China, many problems that they face are also our own. Their culture, strongly rooted in history and tradition, leads them to integrate longstanding solutions, while Western medicine tends towards the new and innovative. Influenced by who they are as a people, each seeks to improve the way its population navigates rural medicine in different ways. But both societies, ultimately, have an unwavering desire to help patients and tackle inequalities present in the way we deliver care - an essential quality of a just and equitable medical system no matter where you are in the world.

\section{REFERENCES}

1. TRADING ECONOMICS. China - Rural population [Internet]. 2019 [cited August 13, 2019]. Available from: https://tradingeconomics.com/china/ rural-population-percent-of-total-population-wb-data.html.

2. Ge, W., Chen, R., Song, W., \& Kan, H. Daily Visibility and Hospital Admission in Shanghai, China. Biomedical and Environmental Sciences. 2019 Apr; 24(2), 117-121. DOI: https://doi.org/10.3967/0895-3988.2011.02.005

3. Goffin, P. Northern Ontarians suffer from poor health and access to care: report [Internet]. The Star. 2017 Apr 18. Available online at: https://www. thestar.com/news/canada/2017/04/18/northern-ontarians-suffer-frompoor-health-and-access-to-care-report.html

4. Oudshoorn, K. Nunavut TB rates remain high despite community testing [Internet]. CBC. 2019 Jun 11. Available online at: https://www.cbc.ca/ news/canada/north/nunavut-tb-rates-remain-high-1.5169300

5. Wang L, Suo S, Li J, et al. An investigation Into Traditional Chinese Medicine Hospitals in China: Development Trend and Medical Service Innovation. Int J Health Policy Manag. 2016 Jun 7;6(1):19-25. doi: 10.15171/ijhpm.2016.72. PubMed PMID: 28005539; PubMed Central PMCID: PMC5193503.

6. Vogel, L. Task force launching to examine national licensure for virtual care [Internet]. CMAJ. 2019 Apr 15; 191(15) E429. DOI: https://doi.org/10.1503/ cmaj.1095738

7. Owens, B. Telemedicine on the rise but lagging in Canada [Internet]. CMAJ. 2018 Sep 24; 190(38) E1149-1150. DOI: https://doi.org/10.1503/cmaj.1095634

8. Vickers, A. J., Vertosick, E. A., Lewith, et al. Acupuncture for Chronic Pain: Update of an Individual Patient Data Meta-Analysis. The Journal of Pain 2018 Dec 2; 19(5), 455-474. https://doi.org/https://doi.org/10.1016/j. jpain.2017.11.005

9. Stahl, J. E., Dossett, M. L., LaJoie, A. S., et al. (2015). Relaxation Response and Resiliency Training and Its Effect on Healthcare Resource Utilization. PloS One, 10(10), e0140212. https://doi.org/10.1371/journal.pone.0140212 